\title{
Low-density lipoprotein-antioxidant flavonoids and a phenolic ester from Plectranthus hadiensis var. tomentosus
}

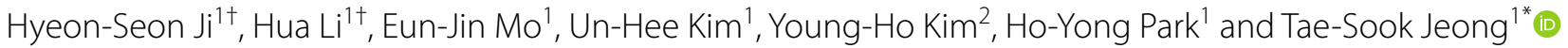

\begin{abstract}
To investigate the effects of extraction solvents and drying methods on Plectranthus hadiensis var. tomentosus quality, eight compounds were isolated and the content of active compounds with their antioxidant activities were compared. Compounds $\mathbf{1}$ and $\mathbf{2}$ were known antioxidants, whereas the low-density lipoprotein (LDL)-antioxidant activities of compounds $\mathbf{3}, \mathbf{5}, \mathbf{6}$, and $\mathbf{7}$ are reported for the first time, with $I C_{50}$ values of $2.5,3.8,22.8$, and $53.7 \mu \mathrm{M}$, respectively. Our analysis of 30-95\% ethanol extracts from freeze- and air-dried leaves and stems revealed a relationship between extract composition and antioxidant activity. The 95\% ethanol extracts of freeze-dried stems (FDS) exhibited highest phenolic and flavonoid content, which were 1.40 and 2.67 times, respectively, greater than those of air-dried stems (ADS), and very high LDL-antioxidant and DPPH radical scavenging activities, which may have resulted from the phenolic ester rosmarinic acid (2), a major component of FDS extracts and potent antioxidant. In contrast, the 95\% ethanol extracts of ADS exhibited relatively low antioxidant activity, possibly owing to the low antioxidant activity of the main components ayanin (7) and (+)-plectranthone (8). These results are important for the development of $P$. hadiensis var. tomentosus as an effective natural antioxidant material.
\end{abstract}

Keywords: Antioxidant, Flavonoid, Phenolic compounds, Plectranthus hadiensis var. tomentosus, Rosmarinic acid

\section{Introduction}

The excess production of oxidants, such as reactive oxygen species, and imbalances between antioxidative defence systems and active oxygen molecules can induce oxidative stress, and such oxidative stress has been linked to the pathogenesis of various chronic diseases, including cardiovascular disease [1], atherosclerosis [2], cancer [3], and inflammatory disorders [4]. Accordingly, the application of antioxidants for the treatment of various pathological diseases has gained the attention of the food, cosmetic, and pharmaceutical industries, as well as of the research community [5]. Furthermore, many natural antioxidants are derived from herbs, spices, tea, and fruits

\footnotetext{
*Correspondence: tsjeong@kribb.re.kr

${ }^{\dagger}$ Hyeon-Seon Ji and Hua Li contributed equally to this work

${ }^{1}$ Industrial Bio-materials Research Center, Korea Research Institute of Bioscience and Biotechnology (KRIBB), 125 Gwahak-ro, Yuseong Daejeon 34141, Republic of Korea

Full list of author information is available at the end of the article
}

[6], and the antioxidant effects of such products are correlated with their polyphenol content $[7,8]$.

Plants of the genus Plectranthus (family Lamiaceae) are used for the treatment of digestive problems, skin disease, infection/fever, pain, and allergies, with a wide diversity of ethnobotanical uses [9]. The Plectranthus plants are enriched in phenolics and essential oils, including terpenoids [10]. However, the phytochemical constituents and biological roles of $P$. hadiensis var. tomentosus (Benth. ex E.Mey.) Codd (PHT), a succulent-like perennial herb found in South Africa and Asia, including South Korea, have been poorly documented. In the present study, we isolated eight compounds from the aerial parts of PHT, and analysed their antioxidant activity by evaluating their ability to inhibit $\mathrm{Cu}^{2+}$-mediated low-density lipoprotein (LDL) oxidation and apoB-100 fragmentation and scavenge 1,1-diphenyl-2-picrylhydrazyl (DPPH) radicals.

Both hot air- and freeze-drying are commonly used for preserving plant products and air-drying can drastically 
reduce the quality of the original material [11]. In addition, the optimized processes of the extraction method using solvents is very important, so that the maximum quantities of active compounds can be obtained for their development and commercialization. Therefore, we evaluated the antioxidant abilities of various ethanol (EtOH) extracts from both freeze- and air-dried PHT leaves and stems.

\section{Materials and methods \\ Plant material}

Aerial parts of PHT were cultivated and collected on August in Daejeon, Korea, and were identified by Dr. Su-Young Kim (Plant Resources Division, National Institute of Biological Resources, Incheon, Korea). A voucher specimen (No. CNU13101) was deposited in the herbarium of the College of Pharmacy, Chungnam National University, Daejeon, Korea.

\section{Instruments and chemicals}

All purifications were monitored on commercially available glass-backed, pre-coated thin-layer chromatography plates (Merck, Darmstadt, Germany) and were visualized under UV at $254 \mathrm{~nm}$ and $365 \mathrm{~nm}$ or stained with $p$-anisaldehyde solution. Medium pressure liquid chromatography (MPLC) was conducted using BiotageIsolera (Biotage $\mathrm{AB}$, Uppsala, Sweden) and a flash $\mathrm{SiO}_{2}$ column (SNAP Cartridge Silica-gel FLASH $40+$ M, $4.0 \times 15.0 \mathrm{~cm}$; Biotage). Column chromatography was performed using Diaion HP-20 resin (250-850 $\mu \mathrm{m}$, Mitsubishi Chemical Co., Tokyo, Japan), silica gel (200-300 mesh, Merck, Germany), octadecyl silica-gel (ODS; ODS-A, $12 \mathrm{~nm}$, S-150 $\mu \mathrm{m}$; Merck), Sephadex LH-20 (25-100 $\mu \mathrm{m}$; GE Healthcare Biosciences, Uppsala, Sweden), and Sep-Pak C18 (Waters Co., Milford, MA, USA). All the solvents used for extraction and isolation were analytical grade and purchased from Sigma-Aldrich (St. Louis, MO, USA).

\section{Extraction and isolation}

Fresh aerial parts of PHT $(3.5 \mathrm{~kg})$ were ground and extracted with $20 \mathrm{~L} 95 \% \mathrm{EtOH}$ for $72 \mathrm{~h}$ at room temperature, and the $95 \% \mathrm{EtOH}$ extract was concentrated in vacuo to yield a brown residue $(48.8 \mathrm{~g})$. The residue was suspended in $10 \%$ aqueous methanol $(\mathrm{MeOH})$ and partitioned with $n$-hexane $(1000 \mathrm{~mL} \times 3)$ and chloroform $\left(\mathrm{CHCl}_{3}\right)(1000 \mathrm{~mL} \times 3)$, successively.

The $n$-hexane layer $(7.5 \mathrm{~g})$ was subjected to medium pressure liquid chromatography (MPLC) using a $\mathrm{SiO}_{2}$ column $(4.0 \times 15.0 \mathrm{~cm})$ with an $n$-hexane-ethyl acetate (EtOAc) gradient of 1:0 to 0:1 (v/v) and a flow rate $20 \mathrm{~mL} / \mathrm{min}$, in order to obtain eight fractions $(\mathrm{H} 1-\mathrm{H} 8)$. Fraction H5 ( $n$-hexane-EtOAc, 1:1, $1.2 \mathrm{~g}$ ) was further separated using another $\mathrm{SiO}_{2}$ column $(2.0 \times 27.0 \mathrm{~cm})$, with $n$-hexane-EtOAc $(7: 1,5: 1,4: 1,2: 1$, and $1: 2, \mathrm{v} / \mathrm{v}$, $250 \mathrm{~mL}$, each), in order to obtain four sub-fractions (H5-1-H5-4). Sub-fraction H5-2 (4:1, $650 \mathrm{mg})$ was purified using Sephadex LH-20 column $(1.5 \times 60.0 \mathrm{~cm})$ eluting with $\mathrm{CHCl}_{3}-\mathrm{MeOH}(1: 20, \mathrm{v} / \mathrm{v})$ and further purified using $\mathrm{SiO}_{2}$ column $(1.0 \times 26.5 \mathrm{~cm})$ with $n$-hexane-EtOAc $(7: 1,6: 1,4: 1, \mathrm{v} / \mathrm{v}, 40 \mathrm{~mL}$, each) to obtain compound 8 (127.4 $\mathrm{mg}$ ) and H5-2-2-3 (4:1, $40.0 \mathrm{mg}$, which was purified using ODS column $(1.0 \times 26.0 \mathrm{~cm})$ with $\mathrm{CHCl}_{3}-\mathrm{MeOH}-\mathrm{H}_{2} \mathrm{O}(5: 3: 1, \mathrm{v} / \mathrm{v} / \mathrm{v})$ to obtain compound $4(9.5 \mathrm{mg})$. Fraction H6 (4:6, $0.7 \mathrm{~g})$ was further separated using $\mathrm{SiO}_{2}$ column $(2.0 \times 27.5 \mathrm{~cm})$ with $n$-hexane-EtOAc $(7: 1,5: 1,4: 1,2: 1$, and $1: 2, \mathrm{v} / \mathrm{v}, 250 \mathrm{~mL}$, each), to obtain five sub-fractions (H6-1-H6-5), and sub-fraction H6-4 (2:1, $323 \mathrm{mg})$ was purified using Sephadex LH-20 column $(1.5 \times 64.0 \mathrm{~cm})$ with $\mathrm{CHCl}_{3}-$ $\mathrm{MeOH}(1: 100, \mathrm{v} / \mathrm{v})$ to obtain compound 7 (42.2 mg).

The $\mathrm{CHCl}_{3}$ layer $\left(2.1 \mathrm{~g}\right.$ ) was subjected to $\mathrm{SiO}_{2}$ column $(3.5 \times 26.0 \mathrm{~cm})$ with $n$-hexane-EtOAc $(5: 1,4: 1,3: 1,2: 1$, $1: 1,1: 3$, and $1: 5, \mathrm{v} / \mathrm{v}, 500 \mathrm{~mL}$, each), in order to obtain seven fractions (C1-C7). Fraction C5 (2:1, $188 \mathrm{mg})$ was further separated using $\mathrm{SiO}_{2}$ column $(2.0 \times 30.0 \mathrm{~cm})$ with $\mathrm{CHCl}_{3}-\mathrm{MeOH}$ (300:1, 200:1, 100:1, and 50:1, v/v, $200 \mathrm{~mL}$, each) to obtain four sub-fractions (C5-1C5-4), and sub-fraction C5-4 (100:1-50:1, $138 \mathrm{mg})$ was purified using Sephadex LH-20 column $(1.5 \times 62.0 \mathrm{~cm})$ with $\mathrm{CHCl}_{3}-\mathrm{MeOH}(1: 10, \mathrm{v} / \mathrm{v})$ to obtain compound 5 (6.0 mg). Fraction C6 (1:1-1:3, $306 \mathrm{mg})$ was further separated using ODS column $(2.2 \times 28.5 \mathrm{~cm})$ with $\mathrm{CHCl}_{3}-\mathrm{MeOH}(1: 1,2: 3,0: 1, \mathrm{v} / \mathrm{v}, 220 \mathrm{~mL}$, each) to obtain six sub-fractions (C6-1-C6-6). Sub-fraction C6-2 (1:1, $98 \mathrm{mg}$ ) was separated using Sephadex LH-20 column $(1.5 \times 60.0 \mathrm{~cm})$ with $\mathrm{MeOH}-\mathrm{H}_{2} \mathrm{O}(1: 1, \mathrm{v} / \mathrm{v})$ and subsequently purified using preparative TLC (RP-18, $20.0 \times 10.0 \mathrm{~cm}$; Merck) with $\mathrm{MeOH}-\mathrm{H}_{2} \mathrm{O}(4: 1, \mathrm{v} / \mathrm{v})$ to obtain compound 3 (12.8 mg). Continually, sub-fraction C6-4 (1:1, $65 \mathrm{mg})$ was purified using $\mathrm{SiO}_{2}$ column $(1.0 \times 28.0 \mathrm{~cm})$ with $\mathrm{CHCl}_{3}-\mathrm{MeOH}(75: 1$ to $1: 1, \mathrm{v} / \mathrm{v})$ to obtain compound 6 (30.4 mg).

The $10 \%$ aqueous $\mathrm{MeOH}$ layer $(24.9 \mathrm{~g})$ was subjected to Diaion HP-20 column $(70.0 \times 40.0 \mathrm{~cm})$ with $\mathrm{MeOH}-\mathrm{H}_{2} \mathrm{O}$ (0:1, 1:4, 2:3, 3:2, 4:1, and 1:0, v/v, 3.0 L, each), in order to obtain six fractions (M1-M6). Fraction M4 (4:1, $1.5 \mathrm{~g})$ was further separated using ODS column $(3.0 \times 30.0 \mathrm{~cm})$ with $\mathrm{MeOH}-\mathrm{H}_{2} \mathrm{O}(1: 3,1: 2$, and 3:1, v/v, $400 \mathrm{~mL}$, each) to obtain five sub-fractions (M4-1-C4-5). Sub-fraction M4-2 (1:3, $300 \mathrm{mg})$ was purified using Sephadex LH-20 column $(1.0 \times 63.0 \mathrm{~cm})$ with $\mathrm{MeOH}-\mathrm{H}_{2} \mathrm{O}(1: 2, \mathrm{v} / \mathrm{v})$ to obtain compound 2 (72.4 mg), and sub-fraction M4-3 $\left(\mathrm{MeOH}-\mathrm{H}_{2} \mathrm{O}\right.$. 1:2-1:1, $\left.900 \mathrm{mg}\right)$ was further separated using Sephadex LH-20 column $(1.0 \times 45.0 \mathrm{~cm})$ with $\mathrm{MeOH}-\mathrm{H}_{2} \mathrm{O}(1: 1, \mathrm{v} / \mathrm{v})$ to obtain compound 1 (50.7 mg). 


\section{Analysis of crude leaf and stem extracts Preparation of crude extracts}

Freeze- and air-drying of PHT leaves and stems were performed using a freeze dryer (Alpha 1-4 LD plus; Marin Christ, Osterode, Germany) and an air dryer (Daihan Labtech Co., Namyangju, Korea) at $60{ }^{\circ} \mathrm{C}$, respectively. The freeze- and air-dried leaves and stems (FDL, FDS, ADL, and ADS, respectively) were extracted with $20 \mathrm{~mL}$ of $30 \%, 50 \%, 70 \%$, and $95 \% \mathrm{EtOH}$ for $48 \mathrm{~h}$ at room temperature, and the extracts were filtered and then dehydrated using a speed-vacuum evaporation system (Thermo Savant, NY, USA). The resulting samples were then analysed to evaluate their major components, total phenolic and flavonoid content, and LDL-antioxidant and DPPH radical scavenging activities.

\section{Determination of total phenolic and flavonoid content}

The total phenolic content of the extracts were measured using a modified version of the Folin-Ciocalteu method [12] and were expressed as mg catechin equivalent (CE) per $g$ extract. The total flavonoid content of the extracts were measured using a modified colorimetric method [13] and were expressed as mg CE per g extract.

\section{HPLC analysis and main component quantification}

In the present study, the characteristic variations in the 30-95\% EtOH extracts of FDL, FDS, ADL, and ADS from PHT were determined using a Shimadzu HPLC system (Shimadzu Co., Tokyo, Japan), equipped with a binary pump delivery system, a photodiode array detector (PDA), and an auto-sampler, and a Brownlee SPP C18 column $(4.6 \times 50 \mathrm{~mm}, 2.7 \mu \mathrm{m}$; PerkinElmer, Inc., Waltham, MA, USA). The injection volume was $5 \mu \mathrm{L}$, and $0.1 \%$ acetic acid in water (solvent $\mathrm{A}$ ) and acetonitrile (solvent B) were used as the mobile phases. The linear gradient elution program was as follows: $5-40 \% \mathrm{~B}$ at 0-15.0 $\mathrm{min}, 40-100 \% \mathrm{~B}$ at $15.0-20.0 \mathrm{~min}, 100-5 \% \mathrm{~B}$ at $20.0-22.5 \mathrm{~min}$, and $5 \% \mathrm{~B}$ at $22.5-25.0 \mathrm{~min}$. The flow rate was $1.8 \mathrm{~mL} / \mathrm{min}$, and the absorbance was $254 \mathrm{~nm}$.

After evaluating the characteristic variations of the eight compounds in the HPLC profiles of the different extracts, compounds 1,2 , and 7 were selected for quantitative analysis. Compounds 1, 2, and 7 that were isolated from the crude extracts of PHT were used as standards, and after being filtered through a $0.45-\mu \mathrm{m}$ membrane filter (Whatman, Wallingford, UK), calibration curves were generated from serial dilutions of the three individual compounds by plotting the concentration of each sample against its HPLC peak area obtaining the slope (s), standard deviation $(\sigma)$, and correlation coefficient $\left(R^{2}\right)$ of each curve. Subsequently, the three individual compounds were quantified (mg/g extract) in the FDS, FDS,
$\mathrm{ADL}$, and ADS extracts using the regression equations of the corresponding standard curves, and validation of the quantification method was conducted, according to the International Conference of Harmonization (ICH)-Q2 guidelines [14].

\section{DPPH radical scavenging activity}

The DPPH radical scavenging activity of the samples was determined by measuring the decolorization of DPPH from the trapping of its unpaired electron, using the procedure described by Kang et al. [15], with slight modifications. Briefly, $190 \mu \mathrm{L}$ fresh DPPH radical solution in $\mathrm{MeOH}$ $(150 \mu \mathrm{M})$ was added to $10 \mu \mathrm{L}$ of each sample and incubated for $40 \mathrm{~min}$ at room temperature. The amount of DPPH radical remaining was then determined by measuring the solution's absorbance at $517 \mathrm{~nm}$ with a model 680 Microplate reader (Bio-Rad, Inc., Hercules, CA, USA). The antioxidant butylated hydroxytoluene (BHT) and L-ascorbic acid were used as positive controls The DPPH radical scavenging activity was expressed as the percent of starting DPPH radical that was scavenged: DPPH radical scavenging activity $(\%)=100 \% \times(1-$ absorbance of sample/absorbance of control).

\section{Inhibition of $\mathrm{Cu}^{2+}$-induced LDL oxidation}

Blood from healthy volunteers was obtained from the Korean Red Cross Blood Center, Daejeon according to the Guidelines of Blood Donation Program for Research. After the plasma was separated by centrifuging the whole blood at low speed, EDTA (0.1\%), $\mathrm{NaN}_{3}(0.05 \%)$, and phenylmethylsulfonyl fluoride $(0.015 \%)$ were added to the plasma, in order to prevent lipoprotein modification. The LDL was isolated from the plasma using discontinuous density gradient ultracentrifugation, as described previously [16].

TBARS assays were performed as described previously [17], with minor modifications. Briefly, $250 \mu \mathrm{L}$ LDL solution $(120 \mu \mathrm{g}$ of protein in PBS) was supplemented with $10 \mu \mathrm{M} \mathrm{CuSO}_{4}$ as an oxidation initiator, and oxidation reactions were performed in screw-capped $5 \mathrm{~mL}$ glass vials at $37{ }^{\circ} \mathrm{C}$ with or without test samples. After $4 \mathrm{~h}$ of incubation, the reactions were terminated by adding $1 \mathrm{~mL} \mathrm{20 \% (v/v)} \mathrm{trichloroacetic} \mathrm{acid,} \mathrm{and} \mathrm{following} \mathrm{pre-}$ cipitation, the mixtures were supplemented with $1 \mathrm{~mL}$ $0.67 \%$ (v/v) tert-butyl alcohol in $0.05 \mathrm{~N} \mathrm{NaOH}$, vortexed, heated for $5 \mathrm{~min}$ at $95^{\circ} \mathrm{C}$, cooled on ice, and centrifuged for $2 \mathrm{~min}$ at $1000 \times g$. Subsequently, the optical density of malondialdehyde (MDA), which was produced by LDL oxidation, was measured at $532 \mathrm{~nm}$. BHT and L-ascorbic acid were used as positive controls in this assay, and calibration was performed using a MDA standard that was prepared from tetramethoxypropane [malondialdehyde bis (dimethyl acetal)]. 
The $\mathrm{Cu}^{2+}$-mediated oxidation of LDL oxidation causes fragmentation of apoB-100. Therefore, we evaluated the ability of isolated compounds to inhibit LDL oxidation by measuring fragmentation of apoB-100 using sodium dodecyl sulphate (SDS)-polyacrylamide gel electrophoresis (PAGE), as described previously [18]. After $\mathrm{Cu}^{2+}$-induced oxidation of $\mathrm{LDL}$, the reaction mixtures were denatured with $3 \%$ SDS, $10 \%$ glycerol, and $2 \mathrm{M} \mathrm{DL-}$ dithiothreitol at $95{ }^{\circ} \mathrm{C}$ for $5 \mathrm{~min}$, and SDS-PAGE (5\%) was performed to detect the apoB-100 fragmentation at $75 \mathrm{~V}$ for $150 \mathrm{~min}$. After electrophoresis, the gel was dried and stained with Coomassie Brilliant Blue R250, and the density $\left(\mathrm{AU} / \mathrm{mm}^{2}\right)$ of each apoB-100 band was measured using a GS-800 densitometer (Bio-Rad) with Bio-Rad Quantity One-4.4.2 software. BHT was used as a positive control.

\section{Statistical analysis}

All values are expressed as mean \pm standard deviation (SD). Significant differences among the groups were assessed by one-way analysis of variance (ANOVA) and Student's $t$-test, using JMP software (SAS Institute Inc., Cary, $\mathrm{NC}$, USA), and $p$ value $<0.05$ was considered significant.

\section{Results and discussion}

\section{Isolation and identification of compounds 1-8}

The 95\% EtOH extract of fresh aerial parts of PHT was fractionated using $n$-hexane, $\mathrm{CHCl}_{3}$, and $10 \%$ aqueous
$\mathrm{MeOH}$. The all three fractions were used for further isolation of active metabolites using repeated $\mathrm{SiO}_{2}$, ODS, and Sephadex LH-20 column chromatographies: two sesquiterpenes (4 and 8 ) and one flavonoid (7) were isolated from the $n$-hexane fraction; three flavonoids $(3,5$, and 6) were isolated from the $\mathrm{CHCl}_{3}$ fraction; and one flavonoid (1) and one phenolic acid (2) were isolated from the $10 \%$ aqueous $\mathrm{MeOH}$ fraction (Fig. 1). Furthermore, the chemical structures of compounds 1-8 were identified as luteolin 7-O-glucuronide (1) [19], rosmarinic acid (2) [20], chrysosplenol D (3) [21], desacetyl plectranthone (4) [22], quercetin 3, 7-dimethyl ether (5) [23], casticin (6) [21], ayanin (7) [23], and (+)-plectranthone (8), the enantiomer of (-)-plectranthone [22], based on ${ }^{1} \mathrm{H}$ and ${ }^{13} \mathrm{C}$ NMR and ESI-MS data, and confirmed through comparison with published spectroscopic data (Fig. 1 and Additional file 1). This is the first report on the isolation of these eight compounds from PHT.

\section{Antioxidant activities of compounds 1-8}

The 95\% EtOH extract of fresh aerial parts of PHT exhibited potent LDL-antioxidant activity $(43.7 \pm 0.6 \%$ inhibition at $20 \mu \mathrm{g} / \mathrm{mL}$ ) and the $n$-hexane, $\mathrm{CHCl}_{3}$, and $10 \%$ aqueous $\mathrm{MeOH}$ fractions exhibited LDL-antioxidant activities with $18.9 \pm 1.8 \%, 94.6 \pm 1.1 \%$, and $23.5 \pm 0.2 \%$ inhibition at $20 \mu \mathrm{g} / \mathrm{mL}$, respectively. In addition, compounds 1-3 and 5-7 exhibited potent LDL-antioxidant activities in the TBARS assays with $\mathrm{IC}_{50}$ values of $2.8,1.5$, $2.5,3.8,22.8$, and $53.7 \mu \mathrm{M}$, respectively, whereas the two<smiles>[R]c1ccc(-c2oc3cc([R])c([R])c(O)c3c(=O)c2[R5])cc1-c1ccc(O)c(O)c1</smiles> 
sesquiterpenes (compounds $\mathbf{4}$ and $\mathbf{8}$ ) were not active, and the $\mathrm{IC}_{50}$ values of the positive control, $\mathrm{BHT}$ and L-ascorbic acid were 1.9 and $60.2 \mu \mathrm{M}$, respectively (Table 1). In the present study, the LDL-antioxidant activities of flavonoids $3,5,6$, and 7 are reported for the first time and the activities of flavonoids $\mathbf{3}$ and $\mathbf{5}$ were much higher than that of $\mathrm{L}$-ascorbic acid.

Typically, LDL-antioxidant activities of phenolics and flavonoids are highly dependent on the configuration, position, and total number of hydroxyl groups [24-26], and indeed, compound 2, which 3,4-dihydroxy, $3^{\prime}, 4^{\prime}$-dihydroxy, exhibited the highest LDL-antioxidant activity and is already known for its LDL-antioxidant activity [27, 28]. Furthermore, when we delineated the LDL-antioxidant activities of the flavonoids 1, 3, and 5-7 according to their structure-activity relationships. (i) a $3^{\prime}, 4^{\prime}$-catechol structure in the B-ring of the flavonoid skeleton strongly enhanced the inhibition of LDLoxidation [29, 30]; (ii) benzene-ring methoxyl groups of phenols, especially A and B-ring methoxyl groups of the flavonol skeleton, decreased LDL-antioxidant activity, as was observed for compounds $\mathbf{1}\left(\mathrm{IC}_{50}=2.8 \mu \mathrm{M}\right)$, $3\left(\mathrm{IC}_{50}=2.5 \mu \mathrm{M}\right), \mathbf{5}\left(\mathrm{IC}_{50}=3.8 \mu \mathrm{M}\right), \mathbf{6}\left(\mathrm{IC}_{50}=22.8 \mu \mathrm{M}\right)$, and $7\left(\mathrm{IC}_{50}=53.7 \mu \mathrm{M}\right)$; and (iii) an A-ring glycosyl group of the flavone skeleton retained or slightly enhanced the antioxidant activity, as indicated by comparing the activities of compounds $\mathbf{1}$ and $\mathbf{5}$.

The inhibition of the oxidative process of compounds 1-3 and 5-7 were evaluated also by the fragmentation of apoB-100 through analysis via SDS-PAGE. We observed

\section{Table 1 Antioxidant activity of compounds 1-8 from PHT}

\begin{tabular}{|c|c|c|}
\hline Compounds & $\begin{array}{l}\text { LDL oxidation } \\
\text { inhibition }\left(\mathrm{IC}_{50}\right. \\
\mu \mathrm{M})^{\mathrm{a}}\end{array}$ & $\begin{array}{l}\text { DPPH radical } \\
\text { scavenging }\left(\mathrm{EC}_{50}\right. \\
\mu \mathrm{M})^{\mathrm{b}}\end{array}$ \\
\hline Luteolin 7-O-glucuronide (1) & $2.8 \pm 0.1$ & $26.2 \pm 0.2$ \\
\hline Rosmarinic acid (2) & $1.5 \pm 0.1$ & $19.0 \pm 0.7$ \\
\hline Chrysosplenol D (3) & $2.5 \pm 0.1$ & $48.3 \pm 0.1$ \\
\hline Desacetyl plectranthone (4) & $\mathrm{NI}$ & $\mathrm{Nl}$ \\
\hline $\begin{array}{l}\text { Quercetin 3,7-dimethyl ether } \\
\text { (5) }\end{array}$ & $3.8 \pm 0.1$ & $31.2 \pm 0.1$ \\
\hline Casticin (6) & $22.8 \pm 0.4$ & $>100$ \\
\hline Ayanin (7) & $53.7 \pm 0.1$ & $>100$ \\
\hline (+)-Plectranthone $(\mathbf{8})$ & $\mathrm{NI}$ & $\mathrm{NI}$ \\
\hline $\mathrm{BHT}$ & $1.9 \pm 0.4$ & $>100$ \\
\hline L-Ascorbic acid & $60.2 \pm 1.3$ & $28.1 \pm 0.4$ \\
\hline
\end{tabular}

Values indicate mean $\pm S D$

$N /$ not inhibited

a $\mathrm{IC}_{50}$ values indicate the concentration $(\mu \mathrm{M})$ of sample that caused $50 \%$ inhibition of $\mathrm{Cu}^{2+}$-mediated LDL oxidation

${ }^{b} \mathrm{EC}_{50}$ values indicate the concentration $(\mu \mathrm{M})$ of sample that scavenged $50 \%$ of the DPPH radical
apoB-100 band for native LDL $(120 \mu \mathrm{g} / \mathrm{mL}$ in PBS) that had been incubated without $5 \mu \mathrm{M} \mathrm{CuSO}_{4}$ (i.e., non-oxidized), but the band was completely absent, when the LDL was incubated with $5 \mu \mathrm{M} \mathrm{CuSO}_{4}$. We also observed that treatment of the native LDL with $5 \mu \mathrm{M}$ of compounds $\mathbf{1 - 3}$ and $\mathbf{5}$ inhibited the $\mathrm{Cu}^{2+}$-induced fragmentation of apoB- 100 by $56.3 \%, 37.7 \%, 77.1 \%$, and $84.6 \%$, respectively, and the positive control (BHT) inhibited the fragmentation of apoB- 100 by $54.0 \%$. In this result, compounds $\mathbf{1}, 3$, and 5 exhibited significantly more activity than compound 2 (Fig. 2). The B-ring hydroxyl groups and position of the $\mathrm{C}$-ring methoxyl group on carbon 3 were critical for the protection of apoB-100 fragmentation from $\mathrm{Cu}^{2+}$-induced oxidation, as shown by compounds 3 and $\mathbf{5}$. However, the effect was inconsistent, since compound 2 failed to exhibit the same protection in either the apoB-100 or TBARS assays. TBARS assay is a good method to measure the amount of oxidized lipid present in a medium; MDA, formed from the breakdown of polyunsaturated fatty acids by lipid hydroperoxidation, reacted with thiobarbituric acid to form a red chromophore and the TBARS was detected at $532 \mathrm{~nm}$ [17]. On the other hand, the $\mathrm{Cu}^{2+}$-induced fragmentation of apoB-100 may result from derivatization of apoB lysine residues by peroxidation products or breakdown products, leading to a net increase of negative charge [18]. The reaction is generally inhibited by radical scavengers, such as $\beta$-mercaptoethanol, BHT, and probucol [31]. Thus, the results of some methods may not indicate the same effects on $\mathrm{Cu}^{2+}$-induced oxidation of LDL.

The radical-scavenging activity of antioxidants against free radicals like the 1,1-diphenyl-2-picrylhydrazyl $(\mathrm{DPPH})$ radical, the superoxide anion radical $\left(\mathrm{O}^{2-}\right)$, the hydroxyl radical $\left(\mathrm{OH}^{-}\right)$, or the peroxyl radical $\left(\mathrm{ROO}^{-}\right)$, is measured to test the ability of natural products to act as free radical scavengers or hydrogen donors. Of these methods, DPPH radical scavenging method is widely used to measure antioxidant capacity as a rapid, simple, and inexpensive method [32]. The phenolic compounds 1-3 and $\mathbf{5}$ were more effective than an antioxidant, BHT at radical scavenging with $\mathrm{EC}_{50}$ values as $26.2,19.0,48.3$, and $31.2 \mu \mathrm{M}$, respectively (Table 1), whereas compounds 4 and 6-8 failed to exhibit DPPH radical scavenging activity. In this assay, L-ascorbic acid, a positive control, exhibited an $\mathrm{EC}_{50}$ of $28.1 \mu \mathrm{M}$.

Typically, DPPH radical scavenging effects of phenolics and flavonoids are highly dependent on the configuration, position, and total number of hydroxyl groups $[24,25]$, and indeed, compound 2, which 3,4-dihydroxy, $3^{\prime}, 4^{\prime}$-dihydroxy, exhibited the highest DPPH radical scavenging effects. Furthermore, when we delineated the DPPH radical scavenging effects of the flavonoids 1, 3, and 5-7 according to their structure-activity 


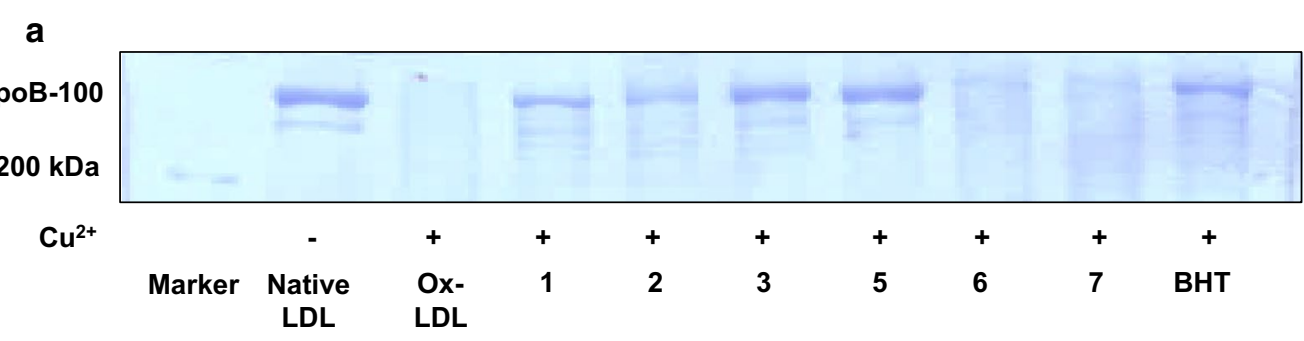

b

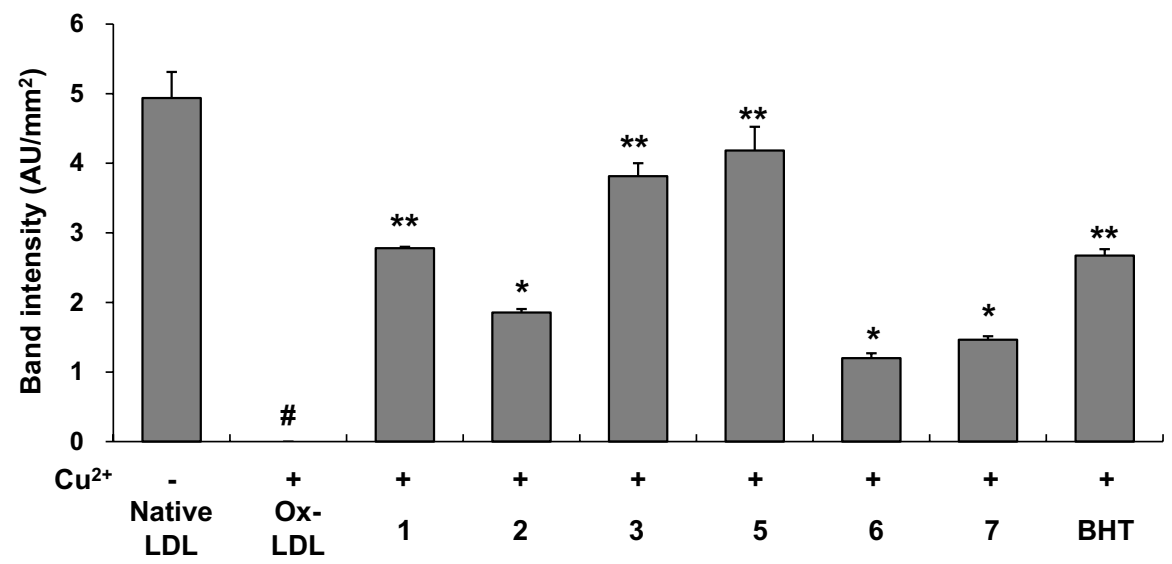

Fig. 2 Antioxidant effects of compounds $\mathbf{1}, \mathbf{2}, \mathbf{3}, \mathbf{5}, \mathbf{6}$, and $\mathbf{7}$ from PHT on $\mathrm{Cu}^{2+}$-mediated apoB-100 fragmentation. a The fragmentation of apoB-100 through analysis via SDS-PAGE. Five $\mu \mathrm{M}$ of each sample was run on an SDS-PAGE and BHT ( $2 \mu \mathrm{M})$ was used as a positive control. $\mathbf{b}$ Intensities of the apoB-100 bands are indicated as mean optical densities (absorbance units $/ \mathrm{mm}^{2}$ ) $\pm S D$ values of three independent experiments. ${ }^{\#} p<0.01$ vs. native $\mathrm{LDL}^{*} p<0.05,{ }^{* *} p<0.01$ vs. ox-LDL using the Student's $t$-test

relationships. (i) a $3^{\prime}, 4^{\prime}$-catechol structure in the B-ring of the flavonoid skeleton strongly enhanced the inhibition of DPPH radical scavenging (ii) benzene-ring methoxyl groups of phenols, especially A and B-ring methoxyl groups of the flavonol skeleton, decreased DPPH radical scavenging effects, as was observed for compounds 1 $\left(\mathrm{EC}_{50}=26.2 \mu \mathrm{M}\right), \mathbf{5}\left(\mathrm{EC}_{50}=31.2 \mu \mathrm{M}\right), \mathbf{3}\left(\mathrm{EC}_{50}=48.3 \mu \mathrm{M}\right)$, $6\left(\mathrm{EC}_{50}>100 \mu \mathrm{M}\right)$, and $7\left(\mathrm{EC}_{50}>100 \mu \mathrm{M}\right)$; and (iii) an A-ring glycosyl group of the flavone skeleton retained or slightly enhanced the antioxidant activity, as indicated by comparing the activities of compounds $\mathbf{1}$ and $\mathbf{5}$.

\section{Characterization of the crude FDL, FDS, ADL, and ADS extracts}

Dry weights (DWs) of 30\%, 50\%, 70\%, and 95\% EtOH extracts of the freeze- and air-dried leaves and stems (FDL, FDS, ADL, and ADS, respectively) of PHT were measured. Regardless of drying type, the DWs of PHT leaf extracts were lower when extracted with higher percentages of $\mathrm{EtOH}$, and the trend was similar for the extracts of stems (Table 2). The DWs of FDL extracts with same solvent were significantly greater than those of the ADL extracts (1.11- to 1.21-fold), but the DWs of FDS and ADS extracts with the same solvent did not have this tendency. In addition, the DWs of FDL extracts were greater than those of the FDS extracts (1.34- to 1.85-fold), and the DWs of the ADL extracts were greater than those of the ADS extracts (1.22- to 2.07-fold).

In regards to total phenolic and flavonoid content expressed as $\mathrm{mg}$ catechin equivalents (CE) per $\mathrm{g}$ extract, we found that the content of the extracts of the freeze- and air-dried leaves and stems (FDL, FDS, ADL, and ADS, respectively) of PHT increased with increasing concentrations of EtOH (Table 2). Regardless of drying type, the total phenolic and flavonoid content of PHT stem extracts were higher than those of PHT leaf extracts. In regards to drying types, the total phenolic and flavonoid content of the freeze-dried leaf and stem extracts (FDL and FDS, respectively) with same solvent were higher than those of air-dried leaf and stem extracts (ADL and ADS, respectively) with same solvent. In addition, the total phenolic content of FDS extracts were higher than those of the FDL extracts (1.15 - to 2.48-fold), and the total flavonoid content of the FDS extracts were greater than those of the FDL extracts (1.02- to 2.43-fold). Among the extracts of the freeze- and air-dried leaves and stems, the 95\% ethanol extracts of freeze-dried stems (95FDS) exhibited 
Table 2 Dry weights and total phenolic and flavonoid content of $30 \%, 50 \%, 70 \%$, and $95 \%$ ethanol extracts from freeze-dried and air-dried leaves and stems of PHT

\begin{tabular}{cccc}
\hline Extracts & $\begin{array}{l}\text { DW of extract } \\
\text { (mg/g dried } \\
\text { material) }\end{array}$ & $\begin{array}{l}\text { Total phenolics } \\
\text { (mg CE/g extract) }\end{array}$ & $\begin{array}{l}\text { Total flavonoids } \\
\text { (mg CE/g extract) }\end{array}$ \\
\hline Leaf & & & \\
30FDL & $324.6 \pm 12.1^{\mathrm{a}}$ & $44.4 \pm 1.1^{\mathrm{d}}$ & $20.7 \pm 0.3^{\mathrm{e}}$ \\
50FDL & $272.8 \pm 4.7^{\mathrm{c}}$ & $98.7 \pm 0.0^{\mathrm{c}}$ & $78.5 \pm 1.3^{\mathrm{c}}$ \\
70FDL & $250.4 \pm 0.2^{\mathrm{d}}$ & $148.0 \pm 3.0^{\mathrm{b}}$ & $116.6 \pm 0.3^{\mathrm{b}}$ \\
95FDL & $145.4 \pm 3.2^{\mathrm{f}}$ & $158.5 \pm 0.2^{\mathrm{a}}$ & $146.3 \pm 0.3^{\mathrm{a}}$ \\
30ADL & $286.8 \pm 3.7^{\mathrm{b}}$ & $20.1 \pm 0.2^{\mathrm{f}}$ & $6.6 \pm 0.3^{\mathrm{g}}$ \\
50ADL & $246.8 \pm 5.4^{\mathrm{d}}$ & $33.9 \pm 1.3^{\mathrm{e}}$ & $15.7 \pm 0.0^{\mathrm{f}}$ \\
70ADL & $207.0 \pm 2.2^{\mathrm{e}}$ & $45.7 \pm 0.2^{\mathrm{d}}$ & $17.0 \pm 0.3^{\mathrm{f}}$ \\
95ADL & $124.6 \pm 4.0^{\mathrm{g}}$ & $48.4 \pm 0.2^{\mathrm{d}}$ & $44.6 \pm 0.5^{\mathrm{d}}$ \\
Stem & & & \\
30FDS & $206.2 \pm 1.0^{\mathrm{a}}$ & $110.1 \pm 0.2^{\mathrm{d}}$ & $50.3 \pm 0.8^{\mathrm{e}}$ \\
50FDS & $203.9 \pm 8.2^{\mathrm{a}}$ & $140.4 \pm 0.0^{\mathrm{b}}$ & $83.5 \pm 1.6^{\mathrm{c}}$ \\
70FDS & $144.4 \pm 1.2^{\mathrm{c}}$ & $179.3 \pm 0.0^{\mathrm{a}}$ & $126.8 \pm 0.0^{\mathrm{b}}$ \\
95FDS & $78.8 \pm 1.5^{\mathrm{d}}$ & $182.1 \pm 2.6^{\mathrm{a}}$ & $149.3 \pm 0.0^{\mathrm{a}}$ \\
30ADS & $209.5 \pm 2.7^{\mathrm{a}}$ & $45.4 \pm 1.5^{\mathrm{f}}$ & $18.9 \pm 0.3^{\mathrm{g}}$ \\
50ADS & $202.5 \pm 6.7^{\mathrm{a}}$ & $56.9 \pm 1.1^{\mathrm{e}}$ & $20.7 \pm 0.3^{\mathrm{g}}$ \\
70ADS & $159.1 \pm 4.2^{\mathrm{b}}$ & $57.7 \pm 2.2^{\mathrm{e}}$ & $24.4 \pm 0.3^{\mathrm{f}}$ \\
95ADS & $60.2 \pm 1.0^{\mathrm{e}}$ & $130.4 \pm 0.4^{\mathrm{c}}$ & $55.9 \pm 0.3^{\mathrm{d}}$ \\
\hline
\end{tabular}

Values indicate mean $\pm S D(n=3)$. DW: dry weight; $C E$ : catechin equivalents $F D L$ freeze-dried leaves, FDS freeze-dried stems, $A D L$ air-dried leaves, $A D S$ airdried stems

a-g Means not sharing a common letter within a column indicate that extracts from the same parts of PHT are significantly different $(p<0.05)$ by one-way ANOVA

highest phenolic and flavonoid content, which were 1.40 and 2.67 times, respectively, greater than those of air-dried stems (ADS). Moreover, we found that the extracts of all four types of plant material contained more total phenolics than total flavonoids (1.08- to 3.05 -fold), regardless of drying method and extraction solvent.

Next, the main components presented in the extracts from PHT were analysed and measured the content using a Shimadzu HPLC system. Compounds 1-8, which were isolated from the extracts of PHT, were used as external standards for the HPLC analysis. The peaks (1-8) of the HPLC profiles were identified as compounds 1-8 (Figs. 3 and 4). For each extraction solvent, the peaks were generally higher in the $95 \% \mathrm{EtOH}$ extracts of FDL, ADL, FDS, and ADS than in the $30 \%, 50 \%$, and $70 \% \mathrm{EtOH}$ extracts of them, at $10 \mathrm{mg} / \mathrm{mL}$. In particular, we found that the extracts of freeze-dried material contained relatively higher concentrations of compounds 1 and 2, whereas the extracts of air-dried material was primarily composed of compounds $\mathbf{7}$ and $\mathbf{8}$. Because compounds $\mathbf{8}$ was not active in the inhibition of LDL-oxidation and DPPH radical scavenging, and the content of main components 1, 2, and 7 in each extract were measured (Table 3).

The calibration curves of compounds $\mathbf{1}, \mathbf{2}$, and 7 exhibited good linearity $\left(R^{2}=0.9986\right.$ to 0.9997 ; Table 4$)$, and the limits of detection and quantification ranged from 0.06 to $0.09 \mu \mathrm{g} / \mathrm{mL}$ and from 0.19 to $0.29 \mu \mathrm{g} / \mathrm{mL}$, respectively. The amount of compound $\mathbf{1}$ was higher in the $50 \%$ and $70 \% \mathrm{EtOH}$ extracts of leaf and stem regardless of drying type than in the $30 \%$ and $95 \% \mathrm{EtOH}$ extracts of them, and was especially high in the $70 \% \mathrm{EtOH}$ extract of FDS (12.67 mg/g extract).

Compound 2, rosmarinic acid, is well known as a main constituent (91.8-154.6 mg/100 g of fresh material weight) of some herbs, including Mexican oregano (Poliomintha longiflora), rosemary (Rosmarinus officinalis), sage (Salvia officinalis), and thyme (Thymus vulgaris) [33]. Rosmarinic acid exhibits antioxidant, anti-inflammatory, antiangiogenic, neuroprotective, antimicrobial, immunomodulatory, and anti-atherosclerotic activities, owing to its antioxidant and radical scavenging properties [34] and resulting in its use in the functional food industry. The amount of compound 2 in the extracts from freeze-dried material was clearly distinguished from the amounts in the extracts of air-dried material, and was significantly higher in the $95 \%$ extracts of FDS (116.05 $\mathrm{mg} / \mathrm{g}$ extract) and FDL $(67.87 \mathrm{mg} / \mathrm{g}$ extract) than in the other extracts of freeze-dried material. In another study, the rosmarinic acid content of EtOH extracts from freeze-dried lemon balm (Melissa officialis L.) leaves was greater than that that of the extracts of hot air-dried leaves $[35,36]$, which is in agreement with the results of the present study. In contrast, the rosmarinic acid content and antioxidant capacity of six Lamiaceous herbs were also investigated after drying the plant material with three different methods (air-dried for 3 weeks at $14{ }^{\circ} \mathrm{C}$ in a dark, well-ventilated room; vacuum oven-dried for $16 \mathrm{~h}$ at $70{ }^{\circ} \mathrm{C}$ and 600 mbar; or freeze-dried for $72 \mathrm{~h}$ at $-54{ }^{\circ} \mathrm{C}$ and $0.064 \mathrm{mbar}$ ), and the authors found that both the rosmarinic acid content and antioxidant capacity were significantly higher in air-dried samples than vacuum oven-dried or freeze-dried samples throughout the 60-day storage period [37]. However, the 3-week, lowtemperature air-drying method was different from the drying methods used in the present study, and the study did not investigate the rosmarinic acid content of $P$. hadiensis var. tomentosus, either.

In contrast to compounds $\mathbf{1}$ and $\mathbf{2}$, the concentration of compound 7 was higher in ADS extracts than in the ADL extracts, as well as the FDS and FDL extracts, and was especially high in the $95 \% \mathrm{EtOH}$ extract of ADS ( $23.86 \mathrm{mg} / \mathrm{g}$ extract). That would be linked to release flavonoids, mainly quercetin derivatives, through air-drying process [38]. 


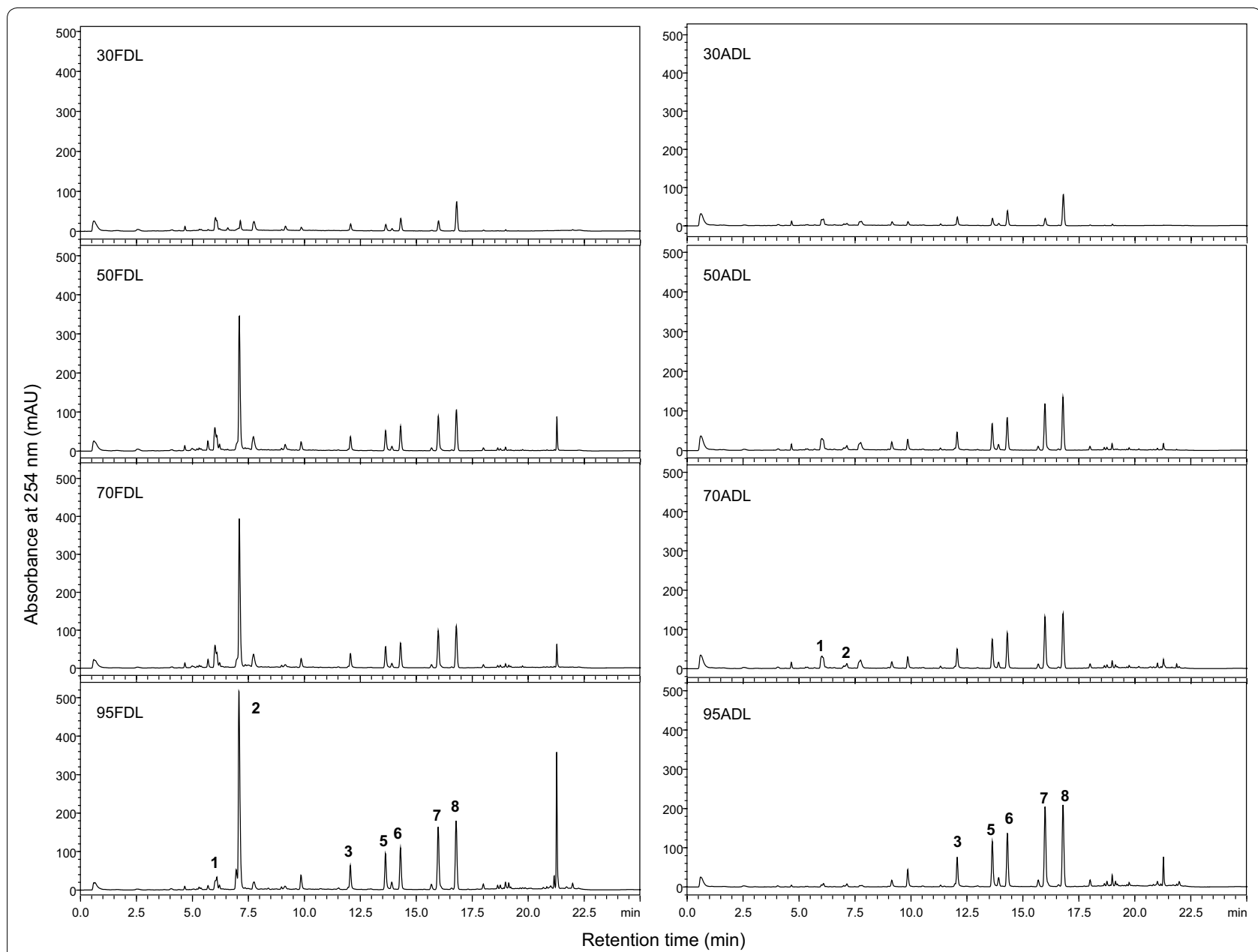

Fig. 3 HPLC chromatograms of 30\%, 50\%, 70\%, and 95\% ethanol extracts (10 mg/mL) from freeze-dried and air-dried leaves of PHT. FDL freeze-dried leaves, $A D L$ air-dried leaves

\section{Antioxidant activities of crude leaf and stem extracts from PHT}

Throughout the present study, the drying method and extraction solvent were strongly correlated with the extraction of the three individual phenolic components, and higher content of compounds $\mathbf{1}$ and $\mathbf{2}$ may responsible for strong antioxidant activity of the extracts. Indeed, we found that the extracts with higher content of compounds $\mathbf{1}$ and $\mathbf{2}$ were more effective as LDL-antioxidants and DPPH radical scavengers than those with lower levels (Table 5).

Among the FDL extracts, the $95 \% \mathrm{EtOH}$ extract exhibited the highest inhibition $(66.4 \%$ at $5 \mu \mathrm{g} / \mathrm{mL})$ of $\mathrm{Cu}^{2+}$-induced oxidation of $\mathrm{LDL}$, followed by the inhibition activity of the $70 \%(43.7 \%$ at $5 \mu \mathrm{g} / \mathrm{mL})$, and $50 \%$ $(33.0 \%$ at $5 \mu \mathrm{g} / \mathrm{mL}) \mathrm{EtOH}$ extracts, respectively. Moreover, the 95\% EtOH extract of FDS exhibited highest inhibition activity $(91.9 \%$ at $5 \mu \mathrm{g} / \mathrm{mL})$ of all the PHT stem extracts, followed by the inhibition activity of the $70 \%$ EtOH extract $(82.6 \%$ at $5 \mu \mathrm{g} / \mathrm{mL})$. In contrast, the extracts of ADL and ADS exhibited relatively weak inhibition activities (below $23.9 \%$ at $5 \mu \mathrm{g} / \mathrm{mL}$ ). Thus, high content of compound 2 in the $70 \%$ and $95 \%$ EtOH extracts of FDL and FDS may responsible for strong LDL-antioxidant activity of the extracts.

In addition, the $95 \%$ and $70 \% \mathrm{EtOH}$ extract of FDS also exhibited the very high DPPH radical scavenging activities $(98.6 \%$ and $91.2 \%$ at $100 \mu \mathrm{g} / \mathrm{mL}$, respectively). 


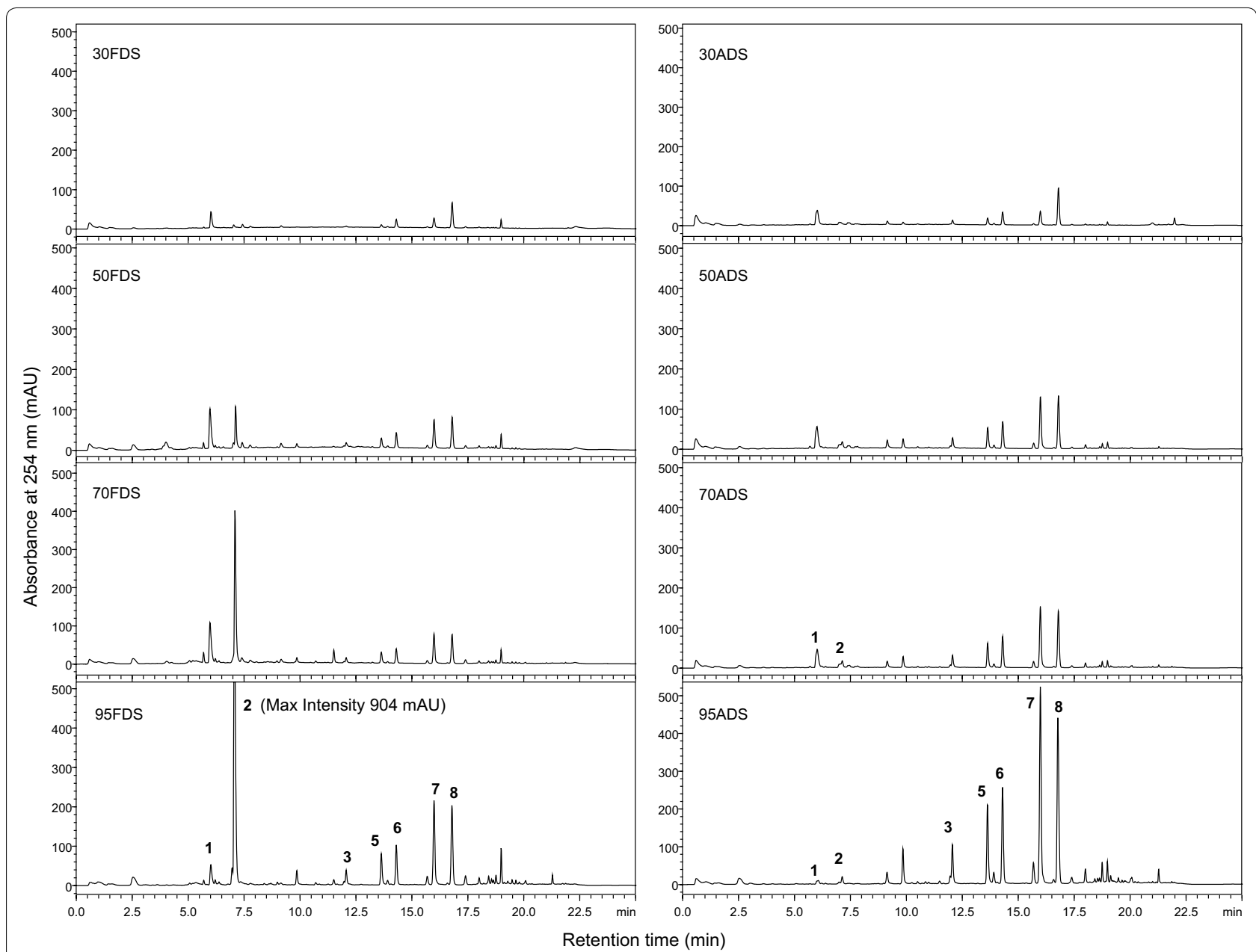

Fig. 4 HPLC chromatograms of 30\%,50\%, 70\%, and 95\% ethanol extracts (10 mg/mL) from freeze-dried and air-dried stems of PHT. FDS freeze-dried stems, ADS air-dried stems

However, among the FDL extracts, the highest radical scavenging activity was exhibited by the $70 \% \mathrm{EtOH}$ extract $(86.9 \%)$, followed by the $50 \%(82.2 \%)$ and $95 \%$ (80.6\%) EtOH extracts. The DPPH radical scavenging activities of the EtOH extracts of ADL and ADS was relatively lower, $21.2-27.6 \%$ inhibition and $32.0-41.9 \%$ at $100 \mu \mathrm{g} / \mathrm{mL}$, respectively, than those of FDL and FDS. Thus, it seems that freeze-drying was more effective than air-drying in preserving the potent antioxidant activities of PHT, which may be related to the higher phenolic content of the extracts of freeze-dried material and the fact that compounds $\mathbf{7}$ and $\mathbf{8}$, which were the major components of the extracts of air-dried material, exhibited relatively low antioxidant activity.
Considering the antioxidant properties demonstrated by both LDL-oxidation and DPPH radical scavenging assays, the $70-95 \% \mathrm{EtOH}$ extract of freeze-dried tissues should be used for the development of a natural antioxidant from PHT.

The present study isolated compounds $\mathbf{1 - 8}$ from the EtOH extract of PHT leaves and stems, and characterized the content and antioxidant activity of 30-95\% EtOH crude extracts of FDL, FDS, ADL, and ADS. Most importantly, LDL-antioxidant and DPPH radical scavenging activity of the flavonoids 3 and 5-7 were reported for the first time, and we suggest that the antioxidant activities of the EtOH extracts of FDL, FDS, ADL, and ADS resulted from the combination 
Table 3 Content of compounds 1, 2, and 7 in the $30 \%$, $50 \%, 70 \%$, and $95 \%$ ethanol extracts from freeze-dried and air-dried leaves and stems of PHT

\begin{tabular}{lccc}
\hline Extracts & \multicolumn{3}{l}{ Contents of compounds (mg/g extract) } \\
\cline { 2 - 4 } & $\mathbf{1}$ & $\mathbf{2}$ \\
\hline Leaf & & $\mathbf{7}$ \\
30FDL & $3.95 \pm 0.02^{\mathrm{cd}}$ & $2.79 \pm 0.01^{\mathrm{d}}$ & $1.38 \pm 0.00^{\mathrm{h}}$ \\
50FDL & $7.25 \pm 0.02^{\mathrm{b}}$ & $39.50 \pm 0.00^{\mathrm{c}}$ & $3.55 \pm 0.00^{\mathrm{f}}$ \\
70FDL & $8.36 \pm 0.01^{\mathrm{a}}$ & $43.22 \pm 0.00^{\mathrm{b}}$ & $3.76 \pm 0.00^{\mathrm{e}}$ \\
95FDL & $1.61 \pm 0.02^{\mathrm{f}}$ & $67.87 \pm 0.00^{\mathrm{a}}$ & $7.54 \pm 0.00^{\mathrm{b}}$ \\
30ADL & $2.12 \pm 0.00^{\mathrm{e}}$ & $0.80 \pm 0.00^{\mathrm{h}}$ & $1.79 \pm 0.00^{\mathrm{g}}$ \\
50ADL & $3.75 \pm 0.27^{\mathrm{d}}$ & $1.59 \pm 0.00^{\mathrm{f}}$ & $5.91 \pm 0.02^{\mathrm{d}}$ \\
70ADL & $4.18 \pm 0.00^{\mathrm{c}}$ & $1.74 \pm 0.00^{\mathrm{e}}$ & $6.42 \pm 0.03^{\mathrm{c}}$ \\
95ADL & $0.58 \pm 0.11^{\mathrm{g}}$ & $0.94 \pm 0.01^{\mathrm{g}}$ & $10.85 \pm 0.08^{\mathrm{a}}$ \\
Stem & & & \\
30FDS & $4.00 \pm 0.26^{\mathrm{e}}$ & $1.05 \pm 1.13^{\mathrm{e}}$ & $0.99 \pm 0.07^{\mathrm{g}}$ \\
50FDS & $10.53 \pm 0.92^{\mathrm{b}}$ & $13.11 \pm 0.96^{\mathrm{c}}$ & $3.65 \pm 0.33^{\mathrm{e}}$ \\
70FDS & $12.67 \pm 0.57^{\mathrm{a}}$ & $48.99 \pm 1.88^{\mathrm{b}}$ & $3.92 \pm 0.19^{\mathrm{e}}$ \\
95FDS & $5.40 \pm 0.10^{\mathrm{d}}$ & $116.05 \pm 1.61^{\mathrm{a}}$ & $10.85 \pm 0.09^{\mathrm{b}}$ \\
30ADS & $5.52 \pm 0.03^{\mathrm{d}}$ & $1.78 \pm 0.01^{\mathrm{de}}$ & $2.01 \pm 0.00^{\mathrm{f}}$ \\
50ADS & $7.37 \pm 0.02^{\mathrm{c}}$ & $3.22 \pm 0.01^{\mathrm{d}}$ & $5.88 \pm 0.03^{\mathrm{d}}$ \\
70ADS & $7.11 \pm 0.00^{\mathrm{c}}$ & $3.51 \pm 0.01^{\mathrm{d}}$ & $7.95 \pm 0.03^{\mathrm{c}}$ \\
95ADS & $1.29 \pm 0.01^{\mathrm{f}}$ & $2.32 \pm 0.03^{\mathrm{de}}$ & $23.86 \pm 0.24^{\mathrm{a}}$ \\
\hline
\end{tabular}

Values indicate mean $\pm S D(n=3)$

$F D L$ freeze-dried leaves, $F D S$ freeze-dried stems, $A D L$ air-dried leaves, $A D S$ airdried stems

a-h Means not sharing a common letter within a column indicate that extracts from the same parts of PHT are significantly different $(p<0.05)$ by one-way ANOVA

of compounds 1-3 and 5-7. In the present study, the 95\% EtOH extract of FDS exhibited the highest total phenolic and flavonoid content, as well as the highest antioxidant activity, as indicated by both TBARS and DPPH radical scavenging assays. However, when considering extraction yield, total phenolic and flavonoid content, and antioxidant activity together, the $70 \%$ EtOH was more suitable and effective for extraction from freeze-dried material. Thus, our findings support
Table 5 Antioxidant activity of $\mathbf{3 0} \%, \mathbf{5 0}, \mathbf{7 0} \%$, and $\mathbf{9 5 \%}$ ethanol extracts from freeze-dried and air-dried leaves and stems of PHT

\begin{tabular}{|c|c|c|}
\hline Extracts & $\begin{array}{l}\text { LDL oxidation inhibition } \\
\text { (\%) at } 5 \mu \mathrm{g} / \mathrm{mL}\end{array}$ & $\begin{array}{l}\text { DPPH radical } \\
\text { scavenging (\%) } \\
\text { at } 100 \mu \mathrm{g} / \mathrm{mL}\end{array}$ \\
\hline \multicolumn{3}{|l|}{ Leaf } \\
\hline 30FDL & $\mathrm{NI}$ & $31.5 \pm 0.1^{c}$ \\
\hline 50FDL & $33.0 \pm 0.0^{c}$ & $82.2 \pm 1.7^{b}$ \\
\hline 70FDL & $43.7 \pm 0.4^{b}$ & $86.9 \pm 1.6^{\mathrm{a}}$ \\
\hline 95FDL & $66.4 \pm 1.4^{\mathrm{a}}$ & $80.6 \pm 1.4^{b}$ \\
\hline $30 A D L$ & $\mathrm{NI}$ & $23.9 \pm 1.1^{\mathrm{e}}$ \\
\hline 50ADL & $5.5 \pm 0.0^{e}$ & $27.6 \pm 0.3^{d}$ \\
\hline $70 \mathrm{ADL}$ & $4.7 \pm 1.3^{e}$ & $25.2 \pm 0.7^{e}$ \\
\hline $95 \mathrm{ADL}$ & $11.1 \pm 1.7^{\mathrm{d}}$ & $21.2 \pm 0.5^{f}$ \\
\hline \multicolumn{3}{|l|}{ Stem } \\
\hline 30FDS & $\mathrm{NI}$ & $31.4 \pm 0.4^{\mathrm{e}}$ \\
\hline 50FDS & $5.8 \pm 0.7^{e}$ & $47.3 \pm 1.2^{c}$ \\
\hline 70FDS & $82.6 \pm 1.4^{b}$ & $91.2 \pm 0.9^{b}$ \\
\hline 95FDS & $91.9 \pm 0.3^{a}$ & $98.6 \pm 0.3^{\mathrm{a}}$ \\
\hline 30ADS & $4.3 \pm 0.9^{d}$ & $32.0 \pm 0.0^{f}$ \\
\hline 50ADS & $16.5 \pm 3.5^{c}$ & $41.9 \pm 1.6^{\mathrm{e}}$ \\
\hline 70ADS & $15.7 \pm 0.9^{d}$ & $39.0 \pm 2.2^{e}$ \\
\hline 95ADS & $23.9 \pm 1.6^{b}$ & $39.0 \pm 1.6^{\mathrm{e}}$ \\
\hline
\end{tabular}

Values indicate mean $\pm S D(n=3)$. Nl: not inhibited

$F D L$ freeze-dried leaves, FDS freeze-dried stems, $A D L$ air-dried leaves, $A D S$ airdried stems

a-f Means not sharing a common letter within a column indicate that extracts from the same parts of PHT are significantly different $(p<0.05)$ by one-way ANOVA

the idea that abundant flavonoids and phenolic acids could have beneficial antioxidant effects in PHT, such beneficial effects would mainly be provided by compound 2, rosmarinic acid, which was the most potent LDL-antioxidant and DPPH radical scavenger among the eight compounds. These findings are important for the development of PHT as an effective natural antioxidant material, which is contained rich phenolic and flavonoid compounds.

Table 4 Quantitative analysis of compounds 1, 2, and 7 in PHT using HPLC-DAD

\begin{tabular}{|c|c|c|c|c|c|c|}
\hline \multirow[t]{2}{*}{ Compounds } & \multicolumn{4}{|l|}{ Linear regression data } & \multirow[t]{2}{*}{$\operatorname{LOD}(\mu \mathrm{g} / \mathrm{mL})$} & \multirow[t]{2}{*}{$\mathrm{LOQ}(\mu \mathrm{g} / \mathrm{mL})$} \\
\hline & Calibration curve & $\mathrm{R}^{2}$ & SD & RSD\% & & \\
\hline 1 & $y=5814.468 x+6319.507$ & 0.9997 & 108.74 & 1.84 & 0.06 & 0.19 \\
\hline 2 & $y=4100.056 x+7260.455$ & 0.9993 & 84.70 & 2.02 & 0.07 & 0.21 \\
\hline 7 & $y=10,254.18 x+22,178.86$ & 0.9986 & 293.48 & 2.76 & 0.09 & 0.29 \\
\hline
\end{tabular}

Values indicate mean \pm SD from two independent experiments performed in triplicate. The limit of detection (LOD) and quantification (LOQ) were determined according to the International Conference of Harmonization (ICH)-Q2 guidelines (ICH. 2005). LOD $=3.3 \delta / S$ and LOQ $=10 \delta / S$, where $\delta=S D$ of the response and $\mathrm{S}=$ slope of the calibration curve 


\section{Supplementary information}

Supplementary information accompanies this paper at https://doi. org/10.1186/s13765-019-0464-y.

Additional file 1: Figure S1. HPLC chromatograms of 95\% EtOH extract (A) and $n$-hexane (B), $\mathrm{CHCl}_{3}(\mathrm{C})$, and $10 \%$ aqueous $\mathrm{MeOH}$ (D) layers from the aerial parts of Plectranthus hadiensis var. tomentosus. Figure S2-S4: ESIMS, ${ }^{1} \mathrm{H}$ NMR, and ${ }^{13} \mathrm{C}$ NMR spectra of compound 1. Figure S5-S7: ESI-MS, ${ }^{1} \mathrm{H} N M R$, and ${ }^{13} \mathrm{C}$ NMR spectra of compound 2. Figure S8-S10: ESI-MS, ${ }_{1}^{1} \mathrm{H}$ NMR, and ${ }^{13} \mathrm{C}$ NMR spectra of compound 3. Figure S11-S13: ESI-MS, ${ }^{1} \mathrm{H}$ NMR, and ${ }^{13} \mathrm{C}$ NMR spectra of compound 4. Figure S14-S16: ESI-MS, ${ }^{1} \mathrm{H}$ NMR, and ${ }^{13} \mathrm{C}$ NMR spectra of compound 5. Figure S17-S19: ESI-MS, ${ }^{1} \mathrm{H}$ NMR, and ${ }^{13} \mathrm{C}$ NMR spectra of compound 6. Figure S20-S22: ESI-MS, ${ }^{1} \mathrm{H}$ NMR, and ${ }^{13} \mathrm{C}$ NMR spectra of compound 7. Figure S23-S26: ESI-MS, ${ }^{1} \mathrm{H}$ NMR, ${ }^{13} \mathrm{C}$ NMR, and NOE spectra of compound $\mathbf{8}$.

\section{Acknowledgements}

This research was supported by the Bio \& Medical Technology Development Program (2016K1A1A8A01938885 and 2016M3A9A5922628) of the National Research Foundation (NRF) and the Creative Allied Project (CAP-18-06-KRIBB) of National Research Council of Science \& Technology (NST) grant by the Korea government (MSIT).

\section{Authors' contributions}

TSJ, HSJ, and HL participated in research design and writing the manuscript; HSJ, HL, EJM, and UHK conducted the experiments; HSJ, HL, YHK, HYP, and TSJ performed data analysis. All authors read and approved the final manuscript.

\section{Availability of data and materials}

The datasets used and/or analysed during the current study are available from the corresponding author on reasonable request.

\section{Competing interests}

The authors declare that they have no competing interests.

\section{Author details}

${ }^{1}$ Industrial Bio-materials Research Center, Korea Research Institute of Bioscience and Biotechnology (KRIBB), 125 Gwahak-ro, Yuseong, Daejeon 34141, Republic of Korea. ${ }^{2}$ College of Pharmacy, Chungnam National University, Daejeon 34134, Republic of Korea.

Received: 11 July 2019 Accepted: 3 October 2019 Published online: 25 October 2019

\section{References}

1. Dhalla NS, Temsah RM, Netticadan T (2000) Role of oxidative stress in cardiovascular diseases. J Hypertens 18:655-673

2. Vogiatzi G, Tousoulis D, Stefanadis C (2009) The role of oxidative stress in atherosclerosis. Hellenic J Cardiol 50:402-409

3. Kawanishi S, Hiraku Y, Murata M, Oikawa S (2002) The role of metals in site-specific DNA damage with reference to carcinogenesis. Free Radic Biol Med 32:822-832

4. Cuzzocrea S, Riley DP, Caputi AP, Salvemini D (2001) Antioxidant therapy: a new pharmacological approach in shock, inflammation, and ischemia/ reperfusion injury. Pharmacol Rev 53:135-159

5. Laguerre M, Lecomte J, Villeneuve P (2007) Evaluation of the ability of antioxidants to counteract lipid oxidation: existing methods, new trends and challenges. Prog Lipid Res 46:244-282

6. Devasagayam TPA, Tilak JC, Boloor KK, Sane KS, Ghaskadbi SS, Lele RD (2004) Free radicals and antioxidants in human health: current status and future prospects. J Assoc Physicians India 52:794-804

7. Chen GL, Chen SG, Xie YO, Chen F, Zhao YY, Luo CX, Gao YO (2015) Total phenolic, flavonoid and antioxidant activity of 23 edible flowers subjected to in vitro digestion. J Func Foods 17:243-259
8. Kähkönen MP, Hopia AI, Vuorela HJ, Rauha JP, Pihlaja K, Kujala TS, Heinonen M (1999) Antioxidant activity of plant extracts containing phenolic compounds. J Agric Food Chem 47:3954-3962

9. Lukhoba CW, Simmonds MSJ, Paton AJ (2006) Plectranthus: a review of ethnobotanical uses. J Ethnopharmacol 103:1-24

10. Abdel-Mogib M, Albar HA, Batterjee SM (2002) Chemistry of the genus Plectranthus. Molecules 7:271-301

11. Ratti C (2001) Hot air and freeze-drying of high-value foods: a review. J Food Eng 49:311-319

12. Sule OS, Megan JB, Kwaku GD (2014) Phenolic composition and bioactive properties of cell wall preparations and whole grains of selected cereals and legumes. J Food Biochem 38:62-74

13. Praveen KR, Awang B (2007) Antioxidant activity, total phenolic and flavonoid content of morinda citrifolia fruit extracts from various extraction processes. J Eng Sci Technol 2:70-80

14. ICH (2005) In: International conference on harmonization of technical requirements for registration of pharmaceuticals for human use; $I \mathrm{CH}$ harmonized tripartite guideline; validation of analytical procedures: text and methodology Q2(R1); finalized guidelines step 4 version: October 1994/November 1996/November 2005 Geneva

15. Kang KA, Lee KH, Zhang R, Piao MJ, Kang MY, Kwak YS, Yoo BS, You HJ, Hyun JW (2007) Protective effects of Castanopsis cuspidate through activation of ERK and NF-KB on oxidative cell death induced by hydrogen peroxide. J Toxicol Environ Health A 70:1319-1328

16. Jeong TS, Kim KS, Kim JR, Cho KH, Lee S, Lee WS (2004) Novel 3,5-diaryl pyrazolines and prazole as low-density lipoprotein (LDL) oxidation inhibitor. Bioorg Med Chem Lett 14:2719-2723

17. Buege JA, Aust SD (1978) Microsomal lipid peroxidation. Methods Enzymol 52:2-10

18. Noguchi N, Niki E (1994) Apolipoprotein B protein oxidation in lowdensity lipoproteins. Methods Enzymol 233:490-494

19. Patora J, Klimek B (2002) Flavonoids from lemon balm (Melissa officinalis L., Lamiaceae). Acta Pol Pharm 59:139-143

20. Lu Y, Foo LY, Wong H (1999) Rosmarinic acid derivatives from Salvia officinalis. Phytochemistry 51:91-94

21. Brown GD, Liang GY, Sy LK (2003) Terpenoids from the seeds of Artemisia annua. Phytochemistry 64:303-323

22. Orabi KY, Mossa JS, Muhammed I, Alloush MH, Galal AM, El-Feraly FS, McPhail AT (2000) New eudesmane sesquiterpenes from Plectranthus cylindraceus. J Nat Prod 63:1665-1668

23. Grayer RJ, Eckert MR, Laver A, Veitch NC, Kite GC, Paton AJ (2010) Distribution of exudate flavonoids in the genus Plectranthus. Biochem Syst Ecol 38:335-341

24. Burda A, Oleszek W (2001) Antioxidant and antiradical activities of flavonoids. J Agric Food Chem 49:2774-2779

25. Heim KE, Tagliaferro AR, Bobilya DJ (2002) Flavonoid antioxidants: chemistry, metabolism and structure-activity relationships. J Nutr Biochem 13:572-584

26. Kwon HS, Kim MJ, Jeong HJ, Yang MS, Park KH, Jeong TS, Lee WS (2008) Low-density lipoprotein (LDL)-antioxidant lignans from Myristica fragrans seeds. Bioorg Med Chem Lett 18:194-198

27. Fuhrman B, Volkova N, Rosenblat M, Aviram M (2000) Lycopene synergistically inhibits LDL oxidation in combination with vitamin $\mathrm{E}$, glabridin, rosmarinic acid, carnosic acid, or garlic. Antioxid Redox Signal 2:491-506

28. Ahmadvand H, Khosrobeigi A, Nemati L, Boshtam M, Jafari N, Hosseini RH, Pournia Y (2012) Rosmarinic acid prevents the oxidation of low density lipoprotein (LDL) in vitro. J Biol Sci 12:301-307

29. Mora A, Paya M, Rios JL, Alcaraz MJ (1990) Structure-activity relationships of polymethoxyflavones and other flavonoids as inhibitors of non-enzymic lipid peroxidation. Biochem Pharmacol 40:793-797

30. Ratty AK, Das NP (1988) Effects of flavonoids on nonenzymatic lipid peroxidation: structure-activity relationship. Biochem Med Metab Biol 39:69-79

31. Tanaka K, Iguchi H, Taketani S, Nakata R, Tokumaru S, Sugimoto T, Kojo S (1999) Facile degradation of apolipoprotein B by radical reactions and the presence of cleaved proteins in serum. J Biochem 125:173-176

32. Prakash A, Rigelhof F, MIller E (2001) Antioxidant activity. Medallion Lab Anal Prog 19:1-4

33. Zheng W, Wang SY (2001) Antioxidant activity and phenolic compounds in selected herbs. J Agric Food Chem 49:5165-5170 
34. Solomon KS, Sandjo LP, Kratz JM, Biavatti MW (2016) Rosmarinic acid -pharmaceutical and clinical aspects. Planta Med 82:388-406

35. Argyropoulos D, Müller J (2014) Effect of convective-, vacuum- and freeze drying on sorption behaviour and bioactive compounds of lemon balm (Melissa officinalis L.). J Appl Res Med Aromat Plants 1:59-69

36. Lin JT, Chen YC, Lee YC, Rolis Hou CW, Chen FL, Yang DJ (2012) Antioxidant, anti-proliferative and cyclooxygenase-2 inhibitory activities of ethanolic extracts from lemon balm (Melissa officinalis L.) leaves. LWT Food Sci Technol 49:1-7

37. Hossain MB, Barry-Ryan C, Martin-Diana AB, Brunton NP (2010) Effect of drying method on the antioxidant capacity of six Lamiaceae herbs. Food Chem 123:85-91
38. Nunes JC, Lago MG, Castelo-Branco VN, Oliveira FR, Torres AG, Perrone D, Monteiro M (2016) Effect of drying method on volatile compounds, phenolic profile and antioxidant capacity of guava powders. Food Chem 197:881-890

\section{Publisher's Note}

Springer Nature remains neutral with regard to jurisdictional claims in published maps and institutional affiliations.

\section{Submit your manuscript to a SpringerOpen ${ }^{\circ}$ journal and benefit from:}

- Convenient online submission

- Rigorous peer review

- Open access: articles freely available online

- High visibility within the field

- Retaining the copyright to your article

Submit your next manuscript at $\mathbf{s p r i n g e r o p e n . c o m ~}$ 